\title{
Studi Skema Proteksi Adaptive Over Current Pada Jaringan Distribusi Dengan Pembangkit Tersebar Menggunakan Genetic Algorithm
}

\author{
Mukhamad Subkhi, Margo Pujiantara, Sjamsjul Anam \\ Jurusan Teknik Elektro, Fakultas Teknologi Industri, Institut Teknologi Sepuluh Nopember (ITS) \\ Jl. Arief Rahman Hakim, Surabaya 60111 Indonesia \\ e-mail:margo@ee.its.ac.id, anam@ee.its.ac.id
}

\begin{abstract}
Abstrak -Dengan berkembangnya renewable energy, seperti energi matahari, energi angin dan air untuk kedepannya akan menjadi sumber energi yang bersih yang mampu menambah daya listrik. Saat ini pembangkit tenaga listrik pada umumnya menggunakan sumber energi batu bara, gas dan minyak bumi sebagai sumber energi utama untuk menghasilkan listrik. Pembangkit-pembangkit tersebut ditinjau dari segi lokasi mempunyai jarak yang sangat jauh dengan pusat beban sehingga biaya untuk membangun sistem distribusi memerlukan biaya yang cukup mahal. Oleh karena di perlukan suatu pembangkit yang tersebar yang lokasinya dekat dengan pusat beban yaitu dengan menambah pembangkit dari renewable energy. Penambahan pembangkit pada jaringan distribusi akan mempengaruhi koordinasi proteksi pada rele arus lebih sehingga diperlukan adanya suatu sistem yang adaptif untuk menangani permasalahn tersebut. Dengan adanya sistem yang adaptif tersebut diharapkan mampu mendeteksi keadaan pembangkit tersebar (distributed generator) apakah tersambung dengan jaringan ataupun tidak. Dengan terdeteksinya distributed generator ke sistem jaringan distribusi pengaturan koordinasi rele akan otomatis berubah sesuai dengan setting rele yang diharapkan.
\end{abstract}

Kata kunci-distributed generator, koordinasi proteksi, pembangkit, rele arus lebih, renewable energy.

\section{PENDAHULUAN}

$\mathrm{P}$ EMbangKitan tenaga listrik di stasiun pembangkit yang di salurkan ke konsumen membutuhkan saluran transmisi dan saluran distribusi. Di tinjau dari segi ekonomi dan lingkungan mengakibatkan fasilitas pembangkit yang berkapasitas besar terletak di daerah pinggiran yang jauh dari pusat beban. Pembangkit yang sumber energi nya menggunakan batubara menimbulkan permasalah polusi terhadap lingkungan sedangkan yang menggunakan sumber energi fosil mempunyai biaya yang sangat mahal dan di prediksi dalam kurun waktu beberapa tahun kedepan sumber energi fosil akan habis [1].

Dengan meningkatnya permintaan energi setiap tahunnya energi listrik tidak dapat terpenuhi karena keterbatasan saluran transmisi. Oleh karena itu diperlukan pembangkit yang efisien seperti pembangkit tersebar (distributed generator). Tingginya biaya transmisi dan distribusi menjadi kendala utama untuk penyaluran tenaga listrik sehingga pengembangan distributed generator menjadi isu yang menarik dikalangan peneliti.. distibuted generator dengan kapasitas daya yang kecil dapat digunakan untuk melayani beban puncak pada jam jam tertentu setiap harinya.[2]
Dengan adanya distributed generator kondisi sistem tenaga listrik menjadi lebih rumit untuk dipahami oleh karena itu sangat diperlukan untuk mengetahui pengaruh pemasangan distributed generator terhadap perubahan di dalam sistem tenaga listrik.[3]. Dari Permasalahan tersebut diperlukan sistem proteksi adaptive yang berguna untuk mengkoordinasi setting rele secara otomatis mengikuti kondisi perubahan status pembangkit tersebar yang masuk ke dalam sistem.

\section{TEORI PENUNJANG}

\section{A. Pembangkit Tenaga Listrik}

Pembangkitan merupakan komponen utama dalam sistem tenaga listrik. Komponen - komponen yang digunakan dalam pembangkitan yaitu generator dan turbin. Dua komponen tersebut berfungsi untuk mengkonversi energi mekanik menjadi energi listrik. Sesaat setelah terjadi pembangkitan energi listrik kemudian dinaikkan tegangannya menggunakan trafo. Menaikkan tegangan merupakan salah satu cara untuk mengurangi rugi daya pada saluran trasnmisi. Tahap selanjutnya saluran distribusi, di Indonesia standart tegangan yang digunakan adalah $20 \mathrm{kV}$ yang nantinya akan diturunkan ke tegangan rendah 380 volt untuk keperluan sehari hari

\section{B. Sistem Distribusi Radial}

Jaringan distribusi radial merupakan jaringan yang paling sederhana dan banyak digunakan di Indonesia. Dinamakan radial karena saluran ini ditarik secara radial dari suatu titik yang merupakan sumber dari jaringan tersebut. Catu daya berasal dari satu titik sumber dan terdapat percabangan untuk membagi beban. Dengan adanya percabangan - percabangan tersebut maka arus beban yang mengalir disepanjang saluran menjadi tidak sama sehingga luas penampang yang digunakan pada saluran berbeda-beda.

\section{Gangguan Sistem Tenaga Litrik}

Dalam sistem tenaga listrik gangguan dapat berupa arus lebih ( overload) dan gangguan hubung singkat ( short circuit). Gangguan ini apabila tidak diatasi dapat merusak peralatan. Gangguan arus lebih Gangguan ini disebabkan karena adanya arus yang mengalir melebihi arus nominal dalam suatu penghantar. Faktor utamanya yaitu kelebihan beban. Gangguan ini apabila tidak segera diperbaiki dapat merusak saluran. Gangguan hubung singkat disebabakan dua faktor yaitu faktor internal dan faktor eksternal. Faktor 
internal berasal dari rusaknya peralatan sistem tenaga listrik. Faktor eksternal berupa cuaca buruk seperti badai, hujan, bencana, runtuhnya pohon dan lain sebagainya. Gangguan hubung singkat menyebabkan terjadinya pemadam apabila tidak di perbaiki gangguan itu menyebabkan terputusnya circuit breaker, penurunan tegangan yang cukup besar sehingga kualitas tenaga listrik menjadi rendah, pengurangan stabilitas sistem dan menyebabkan lepasnya generator dan merusak peralatan pada daerah yang terjadi ganguan.

\section{Algortima Genetika}

Algoritma genetika merupakan metode pencarian dengan menggunakan prinsip proses biologi yaitu evolusi alam. Algoritma ini didasarkan pada proses genetik yang ada pada makhluk hidup, yaitu perkembangan generasi dari awal sampai akhir. Sehingga prinsip seleksi alam yaitu "siapa yang kuat , dia yang bertahan (survive)" menjadi filosofi dari algoritma ini berdasarkan referensi.

Proses metode ini diawali dengan pembangkitan sejumlah populasi secara random sebagai solusi awal. Hasil random awal tersebut akan menjadi induk dari proses generasi selanjutnya. Jika suatu individu memenuhi persyaratan dalam menjalani sebuah proses evolusi, maka individu yang mencapai fungsi tujuan tersebut akan mempunyai kesempatan lebih untuk dipilih menjadi individu terbaik. Sedangkan individu yang tidak sesuai tujuan akan dibuang.

\section{PERANCANGAN SISTEM}

\section{A. Single Line Diagram}

Single line diagram menggunakan dua sumber energi listrik yaitu grid dan distributed generator.

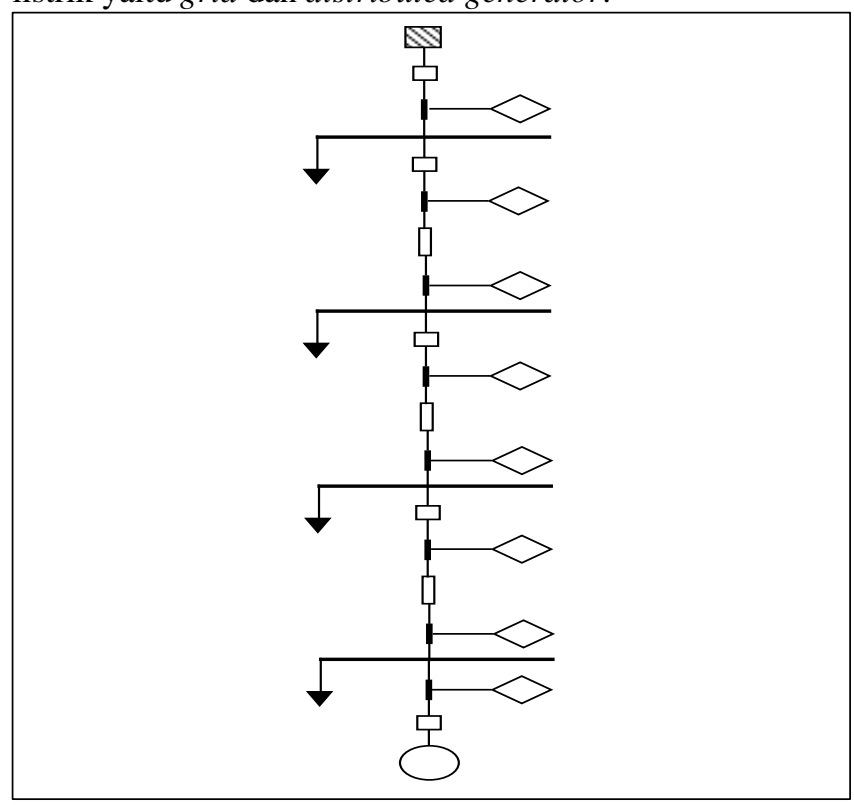

Gambar 1. Single Line Diagram

Single line diagram tersebut mempunyai data - data peralatan diantara grid, distributed generator, kabel, beban dan rasio CT. Lebih jelasnya mengenai data tersebut bisa dilihat pada tabel $1-5$ berikut ini :
Tabel 1.

Data Grid

\begin{tabular}{ccccc}
\hline \hline No & Pembangkit & $\begin{array}{c}\text { MVASc } \\
(\mathbf{m a x})\end{array}$ & MVASc (min) & Tegangan \\
\hline 1 & Grid & 250 & 200 & $13.8 \mathrm{kV}$ \\
\hline \hline
\end{tabular}

Tabel 2.

Data Distributed Generator

\begin{tabular}{ccccc}
\hline \hline No & Pembangkit & Daya (MW) & $\begin{array}{c}\text { Tegangan } \\
(\mathbf{k V})\end{array}$ & PF (\%) \\
\hline 1 & DG1 & 6 & 13.8 & 85 \\
\hline \hline
\end{tabular}

Tabel 3.

Data Kabel

\begin{tabular}{ccccc}
\hline \hline No & Line & R ( $\mathbf{(})$ & $\mathbf{X}(\mathbf{\Omega})$ & Jarak (m) \\
\hline 1. & Line 1-2 & 0.15088 & 0.0973 & 500 \\
2. & Line 2-3 & 0.12169 & 0.0955 & 1000 \\
3. & Line 3-4 & 0.12169 & 0.0955 & 300 \\
\hline \hline
\end{tabular}

Tabel 4.

Data Beban

\begin{tabular}{cccccc}
\hline \hline No & Beban & Bus & MVA & Tegangan (kV) & PF (\%) \\
\hline 1 & Load 1 & 1 & 1 & 13.8 & 90 \\
2 & Load 2 & 2 & 0.5 & 13.8 & 90 \\
3 & Load 3 & 3 & 1 & 13.8 & 90 \\
4 & Load 4 & 4 & 2 & 13.8 & 90 \\
\hline \hline
\end{tabular}

Tabel 5.

Data Rasio CT

\begin{tabular}{ccccc}
\hline \hline No & ID Rele & Arah & Ratio CT & Line \\
\hline 1 & RF1 & Forward & 300 & Line 1-2 \\
2 & RF2 & Forward & 30 & Line 2-3 \\
3 & RR3 & Reverse & 30 & Line 2-3 \\
4 & RF3 & Forward & 50 & Line 3-4 \\
5 & RR2 & Reverse & 50 & Line 3-4 \\
6 & RF4 & Forward & 100 & Line 4-5 \\
7 & RR1 & Reverse & 50 & Line 4-5 \\
\hline \hline
\end{tabular}

\section{B. Konfigurasi Jaringan}

Pada penelitian ini ada tiga konfigurasi jaringan untuk mengatur koordinasi rele :

1. Kondisi jaringan hanya terhubung dengan grid

2. Kondisi jaringan hanya terhubung ke distributed generator

3. Kondisi jaringan terhubung ke grid dan distributed generator

\section{Perancangan Koordinasi Menggunakan Algoritma Genetika}

Koordinasi proteksi menggunakan algoritma genetika diperlukan data awal untuk proses perhitungan, data awal yang dimkasud adalah arus full load, Isc min, Isc max dan ratio ct. 


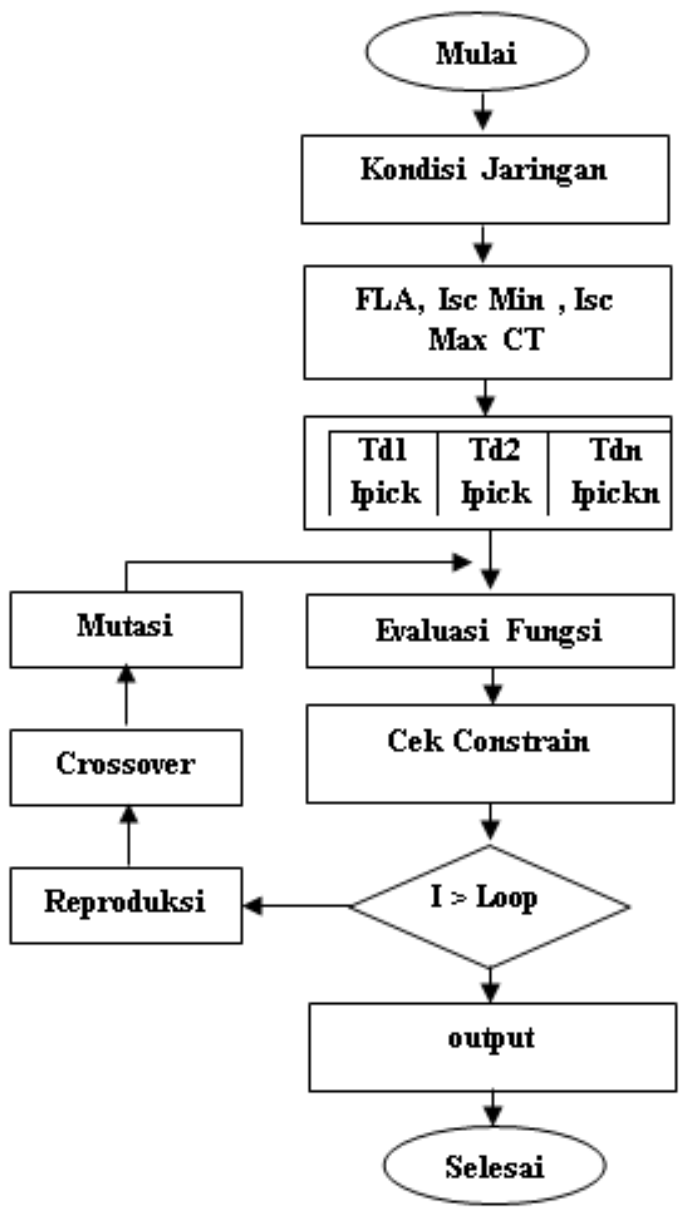

Gambar 2. Flowchart Algoritma Genetika

Berikut merupakan penjelasan dari flowchart diatas :

1. Langkah pertama adalah melakukan sejumlah input data yaitu arus beban penuh yang melewati tiap rele, rasio current transformer yang digunakan serta data arus hubung singkat minimal dan maksimal yang melewati rele. Data didapat dari simulasi dengan menggunakan. Terdapat beberapa data dari konfigurasi topologi yang berbeda. Data-data akan mempunyai status On/Off tergantung topologi yang sedang aktif dengan mengelompokan matriks data pada sejumlah id yang berbeda.

2. Langkah kedua adalah membangkitkan sejumlah data awal yang berupa nilai TD (Time dial) dan Arus pickup (Ipu). Pembangkitan nilai data-data awal ini dilakukan secara random dengan batas-batas yang telah ditentukan. Dalam algoritma genetika nilai TD dan Ipu dikelompokan dalam suatu kromosom dimana jumlah TD beserta Ipu berjumlah sama dengan jumlah rele yang akan dihitung. Adapun batasan dari nilai TD dan Arus pickup atau sering disebut constraint adalah:

$0,05 \leq \mathrm{Td} \leq 1,2$

$>$ 1,05 x Arus Full Load $\leq$ Ipickup $\leq 1,4$ x Arus Full load

3. Langkah ketiga adalah mengevaluasi nilai hasil random kedalam fungsi objektif yaitu:

Min $\mathrm{J}=\sum_{i=1}^{n} \quad w_{\mathrm{i}} \mathrm{t}_{\mathrm{i}}$
Dimana $n$ adalah jumlah rele, $\mathrm{t}_{\mathrm{i}}$ adalah waktu operasi rele saat gangguan sedangkan $\mathrm{w}_{\mathrm{i}}$. Tujuan dari persamaan fungsi tujuan adalah meminimalkan jumlah waktu operasi rele utama.

4. Langkah empat adalah memeriksa nilai-nilai dari hasil evaluasi dengan constraint yang telah ditentukan. Adapun constraint dalam koordinasi proteksi adalah :

a. Selisih waktu kerja rele backup - rele utama saat gangguan pada bus yang sama atau sering disebut coordination time interval (CTI) harus lebih besar dari 0.2 s. Bila $\mathrm{T}_{n k}$ merupakan waktu operasi rele backup pertama $\mathrm{R}_{\mathrm{n}}$ dari gangguan bus $k$ dan $\mathrm{T}_{i k}$ merupakan waktu operasi rele utama $\mathrm{R}_{i}$ maka:

$>\mathrm{T}_{\mathrm{nk}}-\mathrm{T}_{\mathrm{ik}}-\mathrm{CTI} \geq 0$

b. Waktu minimal operasi rele adalah $0.1 \mathrm{~s}$.

5. Langkah kelima yaitu reproduksi. Pada tahap ini, setelah didapat hasil fitness setelah evaluasi dilakukan, maka perlu ditentukan peringkat fitness berdasarkan bobot dari tiap fitness tersebut dengan menggunakan persamaan sebagai berikut:

$$
P(C n)=\frac{\text { Nkeep }-n+1}{\sum_{i=1}^{N k e e p} i}
$$

Dimana Nkeep adalah jumlah ranking serta $\mathrm{n}$ adalah urutan ranking yang dihitung. Sehingga dalam persamaan tersebut akan dihasilkan angka posisi kemungkinan kromosom berada.

6. Langkah selanjutnya adalah crossover. Adapun persamaan yang digunakan untuk menentukan kawin silang adalah:

$$
x_{\text {new }}=(1-\beta) x_{m}+\beta x_{d}
$$

Proses diatas akan berlangsung selama I > Loop, dimana Loop merupakan jumlah iterasi yang telah ditentukan sedangkan I merupakan variabel yang tiap iterasi bertambah 1 nilainya

D. Penyetelan Rele Arus Lebih Waktu Invers dan Instan

Rele arus lebih waktu invers memiliki karakteristik ketika arus gangguan semakin besar, maka waktu operasi rele semakin cepat. Begitu juga sebaliknya, semakin kecil arus gangguan yang terjadi maka waktu operasi rele akan lebih lama. Pada rele arus lebih waktu invers, terdapat dua penyetelan. Penyetelan tersebut adalah setting arus dan waktu. Penyetelan arus dilakukan dengan mengatur tap pada rele yang didapat dengan persamaan sebagai berikut:

Tap $=\frac{\text { Iset }}{\text { CT primary }}$

Penyetelan arus harus mempertimbangkan arus beban maksimal. Hal ini bertujuan agar kondisi ketika beban penuh rele tidak terjadi trip. $\mathrm{I}_{\text {set }}$ merupakan arus pickup dalam Ampere. Berdasarkan standar British BS-142 penyetelan arus pickup mempunyai batas sebagai berikut:

$1,05 \mathrm{I}_{\mathrm{FLA}}<\mathrm{I}_{\mathrm{set}}<1,4 \mathrm{I}_{\mathrm{FLA}}$

Dimana $\mathrm{I}_{\mathrm{FLA}}$ adalah arus beban maksimum peralatan.

Penyetelan waktu dilakukan dengan mengatur time dial untuk mendapatkan waktu operasi rele tersebut. Berdasarkan IEC 255-3, untuk gangguan pada sistem distribusi 
menggunakan jenis kurva standard invers dengan persamaan sebagai berikut berdasarkan referensi [3]:

Di mana :

$$
\mathrm{t}_{\mathrm{d}}=\frac{\mathrm{kxD}}{\left[\left(\frac{\mathrm{I}}{\mathrm{Iset}}\right)^{\alpha}-1\right]}
$$

$t_{d}=$ waktu operasi (detik)

$D=$ time dial

$I$ = nilai arus gangguan (Ampere)

$I_{\text {set }}=$ arus pickup (Ampere)

$k=0,14$

$\alpha=0,02$

Rele arus lebih instan memiliki karakteristik kerja tanpa penundaan waktu, tapi masih bekerja dengan waktu cepat. Jika ada arus lebih yang mengalir melebihi batas yang ditentukan maka rele akan bekerja. Dalam menentukan setelan pickup instan ini digunakan $\mathrm{I}_{\mathrm{sc}}$ min yaitu arus hubung singkat minimum 2 fasa. Sehingga setting ditetapkan:

$I_{\text {set }} \leq 0,8 I_{s c \min }$

\section{SIMULASI DAN ANALISA}

A. Kondisi Jaringan Terhubung Grid

Pada kondisi terhubung ke grid jaringan mempunyai data sebagai berikut :

Tabel 6.

Full Load Ampere

\begin{tabular}{lllll}
\hline \hline No & Bus & $\begin{array}{l}\text { Tegangan } \\
(\mathbf{k V})\end{array}$ & $\begin{array}{l}\text { Beban } \\
(\text { MVA) }\end{array}$ & FLA (A) \\
\hline 1 & Bus1 & 13.8 & 1 & 64.1 \\
2 & Bus2 & 13.79 & 0.5 & 21.9 \\
3 & Bus3 & 13.79 & 1 & 44.5 \\
4 & Bus4 & 13.8 & 2 & 133.2 \\
\hline \hline
\end{tabular}

Tabel 7.

Rele RF4

\begin{tabular}{llccccc}
\hline \hline Jenis & Model & Kurva & $\begin{array}{c}\text { Isc } \\
\text { Max }\end{array}$ & $\begin{array}{c}\text { Isc } \\
\text { Min }\end{array}$ & FLA & CT \\
\hline ABB & REX521 & SI & 7890 & 6820 & 89.3 & 100 \\
\hline \hline
\end{tabular}

\section{Setting Low Set}

$$
\begin{aligned}
& 1.05 \times \text { FLA } \leq \text { IP } \leq 1.4 \times \text { FLA } \\
& 94 \quad \leq \mathbf{I P} \leq 125 \\
& \mathbf{I P}=100 \\
& \text { Tap }=\frac{I P}{C T}=\frac{100}{100}=1
\end{aligned}
$$

\section{Time Dial}

$\mathrm{Tcb}=0.1 \mathrm{~s}$

$$
T d=\frac{\left[\frac{I s c M a x}{I p}\right]^{0.02}-1}{0.14}
$$

$$
T d=\frac{\left[\frac{7890}{100}\right]^{0.02}-1}{0.14}
$$$$
\mathbf{T} \boldsymbol{d}=0.065
$$

\section{High Set}

I set $\leq 0.8 \times$ Isc Min

I set $\leq 0.8 \times 6820$

I set $\leq 5456$

I set $=400$

Tap $=\frac{\text { Iset }}{C T}=\frac{400}{100}=4$

\begin{tabular}{ccccccc}
\multicolumn{7}{c}{ Tabel 8.} \\
Rele RF3 \\
\hline \hline Jenis & Model & Kurva & $\begin{array}{c}\text { Isc } \\
\text { Max }\end{array}$ & $\begin{array}{c}\text { Isc } \\
\text { Min }\end{array}$ & FLA & CT \\
\hline ABB & REX521 & SI & 8150 & 7050 & 133.9 & 150 \\
\hline \hline
\end{tabular}

\section{Setting Low Set}

$$
\begin{aligned}
& \begin{array}{ll}
1.05 \times \text { FLA } & \leq \text { IP } \leq 1.4 \times \text { FLA } \\
141 & \leq \text { IP } \leq 187
\end{array} \\
& \begin{array}{l}
\text { IP }=150 \\
\text { Tap }=\frac{I P}{C T}=\frac{150}{150}=1
\end{array}
\end{aligned}
$$

\section{Time Dial}

$\mathrm{Tcb}=0.3 \mathrm{~s}$

$$
\begin{aligned}
T d & =\frac{\left[\frac{\text { Isc Max }}{I p}\right]^{0.02}-1}{0.14} \\
T d & =\frac{\left[\frac{8150}{150}\right]^{0.02}-1}{0.14} \\
\mathbf{T} \boldsymbol{d} & =0.178
\end{aligned}
$$

\section{High Set}

I set $\leq 0.8 \times$ Isc Min

I set $\leq 0.8 \times 7050$

I set $\leq 5640$

I set $=750$

Tap $=\frac{\text { Iset }}{C T}=\frac{750}{150}=5$

\begin{tabular}{llccccc}
\multicolumn{7}{c}{ Tabel 9. } \\
Rele RF2 \\
\hline \hline Jenis & Model & Kurva & $\begin{array}{c}\text { Isc } \\
\text { Max }\end{array}$ & $\begin{array}{c}\text { Isc } \\
\text { Min }\end{array}$ & FLA & CT \\
& & & & & \\
\hline ABB & REX521 & SI & 9050 & 7880 & 155.8 & 200 \\
\hline \hline
\end{tabular}

\section{Setting Low Set}

$$
\begin{aligned}
& 1.05 \times \text { FLA } \leq \text { IP } \leq 1.4 \times \text { FLA } \\
& 164 \quad \leq \mathbf{I P} \leq 197 \\
& \mathbf{I P}=200 \\
& \text { Tap }=\frac{I P}{C T}=\frac{200}{200}=1
\end{aligned}
$$

\section{Time Dial}

$$
\begin{aligned}
& \mathrm{Tcb}=0.5 \mathrm{~s} \\
& T d=\frac{\left[\frac{\text { Isc Max }}{I p}\right]^{0.02}-1}{0.14}
\end{aligned}
$$


$\begin{aligned} T d & =\frac{\left[\frac{9050}{200}\right]^{0.02}-1}{0.14} \\ \mathbf{T} \boldsymbol{d} & =0.28\end{aligned}$

High Set

I set $\leq 0.8 \times$ Isc Min

I set $\leq 0.8 \times 7880$

I set $\leq 6304$

I set $=1060$

Tap $=\frac{\text { Iset }}{C T}=\frac{1060}{200}=5.3$

Tabel 10.

Rele RF1

\begin{tabular}{lcccccc}
\hline \hline Jenis & Model & Kurva & $\begin{array}{c}\text { Isc } \\
\text { Max }\end{array}$ & $\begin{array}{c}\text { Isc } \\
\text { Min }\end{array}$ & FLA & CT \\
\hline ABB & REX521 & SI & 9550 & 8370 & 197 & 200 \\
\hline \hline
\end{tabular}

\section{Setting Low Set}

$$
\begin{aligned}
& 1.05 \times \text { FLA } \leq \mathbf{I P} \leq 1.4 \times \text { FLA } \\
& 207 \quad \leq \mathbf{I P} \leq 277 \\
& \mathbf{I P}=240 \\
& \text { Tap }=\frac{I P}{C T}=\frac{240}{200}=1.2
\end{aligned}
$$

\section{Time Dial}

$\mathrm{Tcb}=0.7 \mathrm{~s}$

$T d=\frac{\left[\frac{I s c M a x}{I p}\right]^{0.02}-1}{0.14}$

$T d=\frac{\left[\frac{9550}{200}\right]^{0.02}-1}{0.14}$

$\mathbf{T} \boldsymbol{d}=0.4$

\section{High Set}

I set $\leq 0.8 \times$ Isc Min

I set $\leq 0.8 \times 8370$

I set $\leq 6996$

I set $=1600$

Tap $=\frac{\text { Iset }}{C T}=\frac{1600}{200}=8$

\section{B. Perhitungan Menggunakan Genetic Algortihm}

Pada perhitungan ini setting yang pakai hanya pada kondisi low set :

Tabel 11.

Hasil Perhitungan Menggunakan Genetic Algorithm

\begin{tabular}{ccccccc}
\hline \hline ID & \multicolumn{2}{c}{ Setting Lowset } & Arus & \multicolumn{2}{c}{ Setting Highset } & Arus \\
Rele & Tap & TMS & Pick-up & Tap & TD & Pick-up \\
\hline RF1 & 1.16 & 0.6011 & 231.42 & 33.48 & 0.1452 & 6696 \\
RF2 & 0.86 & 0.4095 & 172.34 & 31.52 & 0.3867 & 6304 \\
RF3 & 0.98 & 0.2277 & 146.56 & 37.0 & 0.6850 & 5640 \\
RF4 & 1.06 & 0.0801 & 106.15 & 54.56 & 0.9352 & 5456 \\
& & & & & \\
\hline \hline
\end{tabular}

\begin{tabular}{|c|c|c|c|c|c|c|}
\hline \multirow{3}{*}{$\begin{array}{c}\text { ID } \\
\text { Rele }\end{array}$} & \multicolumn{3}{|c|}{ Algoritma Genetika } & \multicolumn{3}{|c|}{ Manual } \\
\hline & \multicolumn{2}{|c|}{$\begin{array}{l}\text { Setting } \\
\text { Lowset }\end{array}$} & \multirow{2}{*}{$\begin{array}{c}\text { Arus } \\
\text { Pick-up }\end{array}$} & \multicolumn{2}{|c|}{ Setting Lowset } & \multirow{2}{*}{$\begin{array}{c}\text { Arus } \\
\text { Pick } \\
\text { up }\end{array}$} \\
\hline & Tap & TMS & & Tap & TMS & \\
\hline RF1 & 1.16 & 0.6011 & 231.42 & 1.2 & 0.4 & 240 \\
\hline RF2 & 0.86 & 0.4095 & 172.34 & 1 & 0.28 & 200 \\
\hline RF3 & 0.98 & 0.2277 & 146.56 & 1 & 0.178 & 150 \\
\hline RF4 & 1.06 & 0.0801 & 106.15 & 1 & 0.065 & 100 \\
\hline
\end{tabular}

\section{Perbandingan Perhitungan Manual dan Genetic Algotihm}

Tabel 12.

Perbandingan Perhitungan Manual dan Genetic Algorithm

\section{Plotting Kurva}

Dari perhitungan diatas untuk melihat koordinasi proteksinya bisa dilihat pada kurva TCC berikut ini :

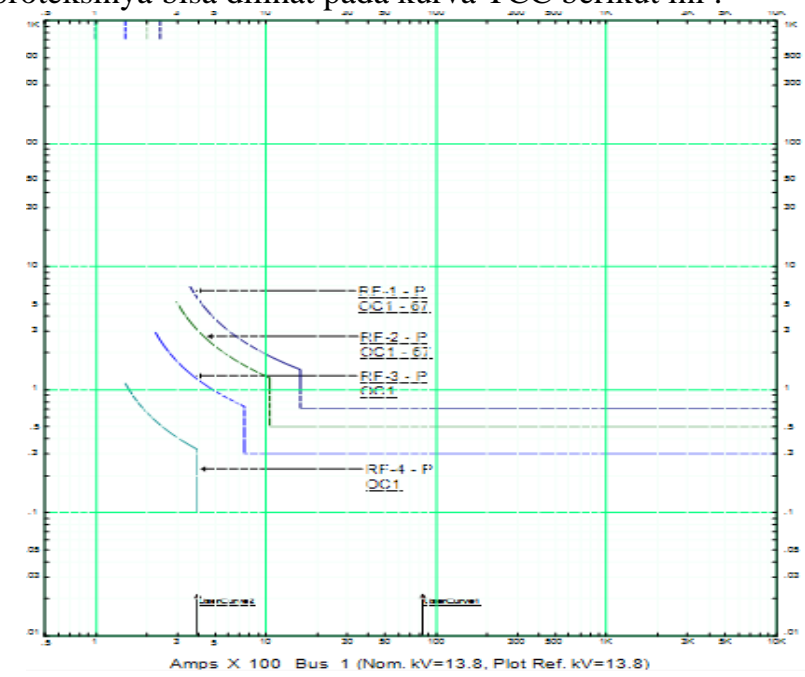

Gambar 3. Kurva Time Current Curve

\section{KESIMPULAN}

Berdasarkan hasil simulasi dan analisa koordinasi proteksi dengan distributed generator menggunakan algoritma genetika dapat diambil beberapa kesimpulan dinataranya :

a. Dengan adanya distributed generator arus hubung singkat di semua bus mengalami kenaikan, sehingga terjadi perubahan setting koordinasi rele.

b. Distributed generator menyebabkan adanya dual arus yang mengalir sehingga diperlukan CT dan rele tambahan untuk mendeteksi arus dari sisi yang berlawanan.

c. Hasil perhitungan manual dan perhitungan menggunakan algoritma genetika terdapat perbedaan pada setting lowset terutama di TMS, namun perbedaan tersebut tidak mempengaruhi koordinasi rele.

d. Pada zona 1-2, 2-3 dan 3-4 terdapat dua rele untuk mendeteksi arus forward yang berasal dari grid dan arus reverse yang berasal dari Distributed generator.

e. Tanpa adanya rele reverse apabila terjadi gangguan di bus waktu tripping akan menjadi lama. 


\section{DAFTAR PUSTAKA}

[1] Noghabi S.Abbas, Sadeh J, Mashhasi R.Habib, "Considering Different Netowrk Topologies in Optimal Overcurrent Relay Coordination Using a Hybrid GA" IEEE Transaction On Power Delivery, Vol. 24 , No.4, Oct 2009.

[2] Felipe A.Contreras, Gustavo A.Ramos, Mario A.Rios, "Methodology and Design of an Adaptif Overcurrent Protection for Distribution Systems with DG" IJECS-IJENS, vol.12 No.05, Oct 2012.

[3] Chen Chao R, Lee Cheng H, Chang Chi J, "Optimal Overcurrent Relay Coordination in Power Distribution System Using a New Approach" Electr Power Energy Syst, vol 45 ,2013. 